ESJ Social Sciences

\title{
Developing Cross-Cultural Competency through Multicultural Perspective: An Exploratory Inquiry
}

\author{
Yvette Pierre \\ Nirmaljit Rathee $K$. \\ Education Department, Delaware State University, Dover, Delaware, USA \\ Vikramjit Rathee $S$. \\ Wrair Silver Spring, Maryland, USA
}

Doi:10.19044/esj.2021.v17n27p324

Submitted: 27 July 2021

Accepted: 30 August 2021

Published: 31 August 2021
Copyright 2021 Author(s)

Under Creative Commons BY-NC-ND

4.0 OPEN ACCESS

Cite As:

Pierre Y., Rathee N. K. \& Rathee V. S. (2021). Developing Cross-Cultural Competency through Multicultural Perspective: An Exploratory Inquiry. European Scientific Journal, ESJ, 17 (27), 324. https://doi.org/10.19044/esj.2021.v17n27p324

\begin{abstract}
For the past decade, schools at all grade levels in United States continue to consist of students who belong to different culture, and hence the need for culturally competent teachers to address the culturally diverse needs of the students is at its highest peak. One of the ways to impart the attributes of cultural competency to preservice teachers, who will become future teachers, to focus on culturally relevant coursework. This study was carried out via an undergraduate multicultural education course which focused on imparting cultural attitude awareness and cultural knowledge attributes of cultural competency to the students. The influence of this course on these attributes of the students was investigated through a Cultural Competence Survey. The results of this study indicate that experiential and practical aspect of multicultural education has a positive impact on increasing the cultural attitude awareness of the students. It is, hence, a focused, experiential, and practical multicultural education coursework to train culturally competent next generation of teachers.
\end{abstract}

Keywords : Cultural Competency, Cultural Attitude Awareness, Cultural Knowledge, K-12, Multicultural, Education, Teachers, School Diversity 


\section{Introduction}

With the rapidly increasing population of ethnically diverse students in K-12 schools throughout the US, the academic success of a culturally diverse student population is more relevant now than it has ever been (Kahu \& Nelson, 2018). Furthermore, the COVID-19 pandemic has exposed and highlighted many racial and economic disparities affecting minority groups in the US (Thakur et al., 2020). This has intensified the call for culturally competent teachers who can effectively implement the elements of culturally responsive and relevant pedagogy. It is important to note that the current approaches to implementing culturally responsive and relevant pedagogy should be considered. Also, the economic, physical, and emotional conditions of the culturally diverse student population have been severely impacted by this pandemic.

Creating and training culturally competent teachers who are well equipped with the knowledge, skills, and dispositions required to effectively address the needs of a culturally diverse student population required for academic success has been an important topic of discussion in recent years. Fasching Varner et al. (2018) question the modest improvement seen in academic achievement on the part of students from historically under represented groups despite the significant attention paid to culturally relevant approaches. Ladson Billings $(2000,2021)$ responds to questions of this nature by asserting that there is a need to change the narrative pointing towards the changes that systems of education underwent after World War II, the Civil War, and natural disasters such as hurricane Katrina. She suggested that the nation's school system must undergo a hard reset. She went further to say we must specifically reset around technology, curriculum, pedagogy, assessment, and parent/community engagement that will support and promote students' culture.

The concept of cultural competence is relevant in several fields and it's not limited to health care, counseling, social work, administration, management, and education. The importance of one's ability to understand, work, serve people from various backgrounds and social identities are essential attributes that are sought after, and as such, individuals must develop these attributes in them. Goodman (2020) points out that this attribute is referred to by an assortment of terms such as cultural competence (Mayfield, 2020), cross-cultural competence (Chiu et al., 2013), multicultural competence (Shallcross et al., 2013), intercultural competence (Bennett, 2019), cultural proficiency (Nuri Robins et al., 2007), and cultural humility (Tervalon \& Murray Garcia, 1998).

However, with respect to teachers, cultural competence is the ability to view cultural differences as an asset. The importance of cultural competence in teaching stem from the fact that it is one of the four dimensions of 
multicultural education along with curriculum reform, equity pedagogy, and social justice (Tehee Melissa \& Isaacs, 2020). Culturally competent teachers create caring learning communities where varied individual and cultural heritages including languages are freely expressed and highly valued. They utilize cultural and individual knowledge about their students, their families, and their communities to design effective instructional strategies that build upon and link the home and school experiences of the students. This is in addition to utilizing images, literature, and other forms of expression that represent students' diverse cultures and backgrounds. Culturally, competent teachers understand, affirm, and use students' home, primary languages, communication styles, and family structures for learning and discipline (Yamada, 2010). They challenge stereotypes, intolerance, and solidify the importance of cultural diversity through scientific and data-driven discourse. Culturally competent teachers serve as effective change agents by providing critical knowledge and acting in the school system as well as outside to address the inequities distinguished by (but not limited to) race, language, culture, socioeconomics, family structure, and gender (Min et al., n.d.).

Teacher education programs play a vital role in producing active culturally competent teachers who possess the knowledge, skills, and dispositions necessary to effectively address the academic, social, and emotional needs of the culturally diverse student population (Hodge \& Collins, 2019; Min et al., n.d.). For this reason, the education departments in universities across the US have been offering targeted courses in multicultural education to students who are on track to become next-generation teachers. The objective of the multicultural course is to examine the cultural and ethnic differences in values and the implications for classroom instruction and curriculum development. This course examines the implications of cultural and ethnic differences for program planning in classrooms, schools, and school districts. The conceptual framework that guides the multicultural education course curriculum consists of four dimensions: equity pedagogy, curriculum reform, multicultural competence, and social justice. Four principles such as : cultural pluralism, antiracism, culture in teaching, learning, excellence and equity provide the basic premise and philosophy that underlie the conceptual framework (Bennett, 2019).

This paper analyzes such multicultural education course that was offered by the Education Department at the Delaware State University, USA. It is also a curricular requirement for the education majors. In brief, the objective of this multicultural education course was to incorporate two attributes of cultural competency namely; cultural attitude awareness and cultural knowledge (Drame et al., 2021; Hultsjö et al., 2019). These are essential for teachers teaching culturally diverse students in the schools (Civitillo et al., 2018). Throughout the course, the students engage in reading 
assignments, writing assignments, group activities, presentations, documentary reviews, and data analysis. Recently, a school district/community research project was also added to the course content. This project include diverse activities such as group collaboration, exploratory inquiry and critical reflection. Howard (2003) points out that such critical teacher reflection is essential to culturally relevant pedagogy because these can ultimately measure teachers' level of concern and ability to care for their students. A teacher's willingness to ask tough questions about his or her attitudes toward diverse students can reflect a true commitment that the individual has toward students' academic success and emotional well-being. Such exercises are highly essential and useful for developing cultural competency among the teachers (Ewing et al., 2018).

The purpose of this study is to assess the influence of completing the multicultural course on the attributes of cultural competence of the students and to explore the mediating factors affecting cultural attitude awareness and cultural knowledge, which are the two attributes of cultural competence.

\section{Methodology}

The subjects of the study included two groups of undergraduate students of Education Major at the Delaware State University. Group 1 ('WithTE' = Yes) comprises of 16 students who have completed a multicultural education course, and students who have completed a community exploration research project. They engaged in various school district agencies/organizations that were associated with K-12 children to identify and evaluate their strengths and assets about the issues affecting the students' life outside the school and their families. Further, the students discussed the real world problems of the societal inequalities and their reflective experiences with their peer group. On the other hand, Group 2 ('WithTE' = No) comprises of 13 students, who had not completed this course at the time of data collection.

To assess the cultural competence of the students in the two groups, cultural competence survey (Chiang, 2013) was utilized. The content validity of this questionnaire had been established by Chiang (2013) via content validity study by a panel of experts, and a pilot test of the questionnaire was conducted to test the reliability of this instrument. An internal consistency study had also been conducted (Chiang, 2013) to assess the reliability of questions measured on an interval/ratio scale. According to the results of the reliability statistics, the Cronbach's Alpha of Chiang (2013) questionnaire was 770 , which indicated that the design of this survey questionnaire was acceptable.

The questions of the survey offered answer choices based on a sixpoint Likert scale as follows: Strongly agree 6, Agree 5, Somewhat agree 4, 
Somewhat disagree 3, Disagree 2, Strongly disagree 1. The six-point Likert scale was chosen as it has been previously shown to result in better quality data as it enforces participants to put thought into questions and answer choices (Krzych, 2021). The survey tested two attributes of cultural competency which were cultural attitude awareness and cultural knowledge. Q1-Q14 tested for cultural attitude awareness, while Q15-Q24 tested for cultural knowledge. It should be noted that "Culture", as referred here, with regards to cultural competency may include racelethnicity, but is not limited to gender differences, age, religion, disabilities, and sexual orientation. Moreover, the student group ('WithTE' = Yes and 'WithTE' $=$ No) in the tables and figures presented in this paper refer to Group 1 and Group 2, respectively. Here, 'WithTE' refers to student receiving culturally relevant learning teaching experience during their multicultural education course (EDUC 318). Questions of the Cultural Competence Survey are depicted inError! Reference source not found. and analysis of survey data presented in the results and discussion section of this article was performed utilizing SPSS software (IBM Corp., n.d.). 
Table 1: Cultural Competency Survey Questions

\begin{tabular}{cc}
\hline Iter & Questions \\
\hline Q1 & Cultural heritage has influenced the way I think \\
Q2 & I am always conscious of the cultural knowledge I use when interacting with people of varying cultural backgrounds \\
Q3 & I need to examine my own identity \\
Q4 & I can be a friend of someone culturally different from myself \\
Q5 & I am never able to recognize my biases regarding others \\
Q6 & My background (in terms of gender, ethnicity, religion etc.) affects how I view myself \\
Q7 & I am sensitive to situations (on campus or in other areas) that are not welcoming to members of certain groups \\
Q8 & I become more aware of cultural differences when I interact with people from a culture that is unfamiliar to me \\
Q9 & I have trouble recognizing intolerance among my peers \\
Q10 & I look forward to a serious discussion with others whose beliefs are different from my own \\
Q11 & I am aware of my initial reactions toward persons from different cultural backgrounds \\
Q12 & I have opportunities to interact with people from other cultural and ethnic groups \\
Q13 & I plan to have academic coursework, fieldwork experiences, or research projects related to culturally diverse groups in the future \\
Q14 & My past (or future) employment brought (or will bring) me into contact with diverse cultural groups \\
Q15 & I know about issues related to gender in the US \\
Q16 & I am unfamiliar with the barriers that people with disabilities face \\
Q17 & I understand the cultural values and religious beliefs of other cultural groups \\
Q18 & I am not knowledgeable about issues related to sexual orientation (homosexuality, heterosexuality, bi-sexuality, trans-gender) \\
Q19 & I am familiar with the term 'prejudice' \\
Q20 & I have limited knowledge of the term 'cultural diversity' \\
Q21 & Older people do not tend to face discrimination in society \\
Q22 & I am not knowledgeable about the arts and crafts of other cultures \\
Q23 & I understand the term 'affirmative action' \\
Q24 & An individual's socioeconomic status is related to the development of their values \\
\hline
\end{tabular}




\section{Reliability Tests}

To reestablish the reliability of the Cultural Competence Survey (Chiang, 2013) due to the time-lapse, Cronbach's Alpha which is commonly used as a measure of internal consistency was utilized to indicate consistency among the variables in a summated scale (Hair, 2010). The rationale for internal consistency for a Likert scale survey is that the individual items or indicators of the scale should all be measuring the same construct, and thus should be highly intercorrelated (Hair, 2010). Another commonly used assessment for the degree of consistency is test-retest which measures the responses of an individual at two points in time to check if the responses do not vary too much (Vilagut, 2014). However, since the purpose of this study was to evaluate the influence of a multicultural education course on the cultural competency of the students, but not the retention of acquired cultural competency, the test-retest was not utilized.

To start with, the reliability test was completed for the sub-scale of cultural attitude awareness (Q1-Q14) (seeError! Reference source not found.). Following the recommendations of Pallant (2020), Item-Total correlations of less than 0.3 were excluded. Hence, Q3, Q4, Q5, Q9, and Q10 were removed. Note that the term 'Item' and 'Questions' are used interchangeably here and throughout the paper. The resulting scale showed a Cronbach's Alpha of 0.829 (see Table 2), which is above the acceptable levels (Hair, 2010) and the resulting Item-Total correlations were all above 0.400 (see

Table 3$).$ In contrast, the reliability test for the sub-scale of cultural knowledge including all questions (Q15-Q24) resulted in 8 out of 10 items with Item-Total correlations below 0.3 (see

Table 4). Hence, the reliability test was redone after excluding items with correlations lower than 0.1 instead of 0.3. The resulting scale showed approximately acceptable Cronbach's Alpha of 0.644 (see Table 5). The resulting Item-Total correlations are shown in Table 6.

Table 1: Item-Total Statistics

\begin{tabular}{cccccc}
\hline & $\begin{array}{c}\text { Scale Mean if } \\
\text { Item Deleted }\end{array}$ & $\begin{array}{c}\text { Scale Variance } \\
\text { if Item Deleted }\end{array}$ & $\begin{array}{c}\text { Corrected } \\
\text { Item-Total } \\
\text { Correlation }\end{array}$ & $\begin{array}{c}\text { Squared } \\
\text { Multiple } \\
\text { Correlation }\end{array}$ & $\begin{array}{c}\text { Cronbach's } \\
\text { Alpha if Item } \\
\text { Deleted }\end{array}$ \\
\hline Q1 & 59.55 & 35.899 & .655 & .954 & .668 \\
Q2 & 59.28 & 39.993 & .452 & .906 & .700 \\
Q3 & 58.90 & 46.382 & .117 & .627 & .733 \\
Q4 & 58.03 & 48.892 & -.159 & .806 & .742 \\
Q5 & 61.52 & 45.973 & .070 & .705 & .744 \\
Q6 & 59.41 & 35.608 & .549 & .834 & .683 \\
Q7 & 59.07 & 38.567 & .520 & .888 & .690 \\
Q8 & 58.52 & 39.973 & .694 & .871 & .681 \\
Q9 & 61.72 & 43.064 & .290 & .849 & .720 \\
Q10 & 59.03 & 50.749 & -.234 & .897 & .784
\end{tabular}




\begin{tabular}{llllll} 
Q11 & 58.69 & 44.365 & .512 & .778 & .710 \\
Q12 & 58.48 & 43.759 & .494 & .857 & .708 \\
Q13 & 59.17 & 36.576 & .529 & .792 & .687 \\
Q14 & 58.38 & 43.530 & .506 & .857 & .706 \\
\hline
\end{tabular}

Table 2 : Reliability Statistics

\begin{tabular}{ccc}
\hline & $\begin{array}{c}\text { Cronbach's Alpha } \\
\text { Based on Standardized } \\
\text { Items }\end{array}$ & $\mathrm{N}$ of Items \\
\hline .829 & .853 & 9 \\
\hline
\end{tabular}

Table 3 : Item-Total Statistics

\begin{tabular}{cccccc}
\hline & $\begin{array}{c}\text { Scale Mean if } \\
\text { Item Deleted }\end{array}$ & $\begin{array}{c}\text { Scale Variance } \\
\text { if Item Deleted }\end{array}$ & $\begin{array}{c}\text { Corrected } \\
\text { Item-Total } \\
\text { Correlation }\end{array}$ & $\begin{array}{c}\text { Squared } \\
\text { Multiple } \\
\text { Correlation }\end{array}$ & $\begin{array}{c}\text { Cronbach's } \\
\text { Alpha if Item } \\
\text { Deleted }\end{array}$ \\
\hline Q1 & 39.62 & 30.315 & .676 & .880 & .794 \\
Q2 & 39.34 & 33.877 & .490 & .849 & .817 \\
Q6 & 39.48 & 30.544 & .531 & .584 & .819 \\
Q7 & 39.14 & 31.837 & .616 & .705 & .802 \\
Q8 & 38.59 & 33.823 & .757 & .759 & .794 \\
Q11 & 38.76 & 38.618 & .490 & .719 & .824 \\
Q12 & 38.55 & 38.399 & .427 & .475 & .825 \\
Q13 & 39.24 & 30.833 & .553 & .765 & .814 \\
Q14 & 38.45 & 36.970 & .606 & .713 & .814 \\
\hline
\end{tabular}

Table 4 : Item-Total Statistics

\begin{tabular}{cccccc}
\hline & $\begin{array}{c}\text { Scale Mean } \\
\text { if Item } \\
\text { Deleted }\end{array}$ & $\begin{array}{c}\text { Scale } \\
\text { Variance if } \\
\text { Item } \\
\text { Deleted }\end{array}$ & $\begin{array}{c}\text { Corrected } \\
\text { Item-Total } \\
\text { Correlation }\end{array}$ & $\begin{array}{c}\text { Squared } \\
\text { Multiple } \\
\text { Correlation }\end{array}$ & $\begin{array}{c}\text { Cronbach's } \\
\text { Alpha if } \\
\text { Item } \\
\text { Deleted }\end{array}$ \\
\hline Q15 & 32.66 & 24.663 & .010 & .725 & .474 \\
Q16 & 34.97 & 22.320 & .122 & .511 & .456 \\
Q17 & 32.59 & 23.966 & .067 & .533 & .465 \\
Q18 & 33.83 & 14.862 & .600 & .786 & .215 \\
Q19 & 32.38 & 22.244 & .220 & .436 & .427 \\
Q20 & 35.45 & 23.828 & -.030 & .492 & .512 \\
Q21 & 35.10 & 22.810 & .114 & .639 & .457 \\
Q22 & 34.10 & 18.596 & .423 & .719 & .340 \\
Q23 & 33.34 & 22.520 & .067 & .693 & .480 \\
Q24 & 33.55 & 20.399 & .218 & .473 & .423 \\
\hline
\end{tabular}

Table 5 : Reliability Statistics

\begin{tabular}{ccc}
\hline & $\begin{array}{c}\text { Cronbach's Alpha } \\
\text { Based on Standardized } \\
\text { Items }\end{array}$ & N of Items \\
\hline .644 & .638 & 4 \\
\hline
\end{tabular}


Table 6 :Item-Total Statistics

\begin{tabular}{cccccc}
\hline & $\begin{array}{c}\text { Scale Mean if } \\
\text { Item Deleted }\end{array}$ & $\begin{array}{c}\text { Scale Variance } \\
\text { if Item Deleted }\end{array}$ & $\begin{array}{c}\text { Corrected } \\
\text { Item-Total } \\
\text { Correlation }\end{array}$ & $\begin{array}{c}\text { Squared } \\
\text { Multiple } \\
\text { Correlation }\end{array}$ & $\begin{array}{c}\text { Cronbach's } \\
\text { Alpha if Item } \\
\text { Deleted }\end{array}$ \\
\hline Q16 & 12.34 & 9.591 & .297 & .094 & .656 \\
Q18 & 11.21 & 6.027 & .563 & .400 & .466 \\
Q19 & 9.76 & 10.261 & .337 & .126 & .633 \\
Q22 & 11.48 & 7.544 & .547 & .374 & .485 \\
\hline
\end{tabular}

Finally, the scales were calculated by averaging the scores of the items that composed the two scales. An overall scale of 'Cultural Competence' was tested for reliability, but the initial solution indicated poor correlations for all items related to cultural knowledge. Thus, the subsequent tests of these reports will be executed only for the two sub-scales corresponding to the cultural attitude awareness and cultural knowledge attribute respectively, since a single scale would not be reliable.

The student demographics data included only Age and Race. The students in both groups belonged to diverse cultural backgrounds. In Group 1, 12 participants were African American; 2 were Caucasian; and 2 were biracial/multiracial. In Group 2, 4 participants were African American and 9 were Caucasian. Concerning Age, Group 1 comprises of 11 students in the 1820 years category, 3 students in the 21-24 years category, and 2 students in the 31 or older category. However, in Group 2, we have 10 students in the 18-20 years category and 3 students in the 21-24 years category. It is worth noting here that we are not including racial factors with regards to the cultural competency of an individual in the current study, since a separate exhaustive study involving a large population sample would be required for thorough and insightful analysis for this sensitive variable. We recommend this explorative facet with regards to cultural competency for future studies.

\section{Results and Discussions \\ Influence of Multicultural Education Course}

In order to find out the influence of multicultural education course on the attributes of cultural attitude awareness and cultural knowledge of the students, an independent T-tests to compare Group 1 and Group 2 was utilized (IBM Corp n.d. Pallant, 2020).

The results depicted in Table 7 and

Table 8 indicate significant difference between the groups for cultural awareness $(\mathrm{t}=3.338, \mathrm{p}<.01)$ but not for cultural knowledge $(\mathrm{t}=-0.090, \mathrm{p}=$ .929). These results suggest that students who had completed the multicultural 
education course showed significantly higher scores for cultural awareness $($ Mean $=5.222)$ compared to students who did not take the course $($ Mean $=$ 4.453). However, the difference in scores for cultural knowledge was not statistically significant.

Table 7 : Group Statistics

\begin{tabular}{lccccc}
\hline & WithTE & $\mathrm{N}$ & Mean & Std. Deviation & Std. Error Mean \\
\hline \multirow{2}{*}{ Cultural Awareness } & Yes & 16 & 5.2222 & .61531 & .15383 \\
& No & 13 & 4.4530 & .61941 & .17179 \\
\hline \multirow{2}{*}{ Cultural Knowledge } & Yes & 16 & 3.7188 & 1.09116 & .27279 \\
& No & 13 & 3.7500 & .66927 & .18562 \\
\hline
\end{tabular}

Table 8: Independent Samples Test

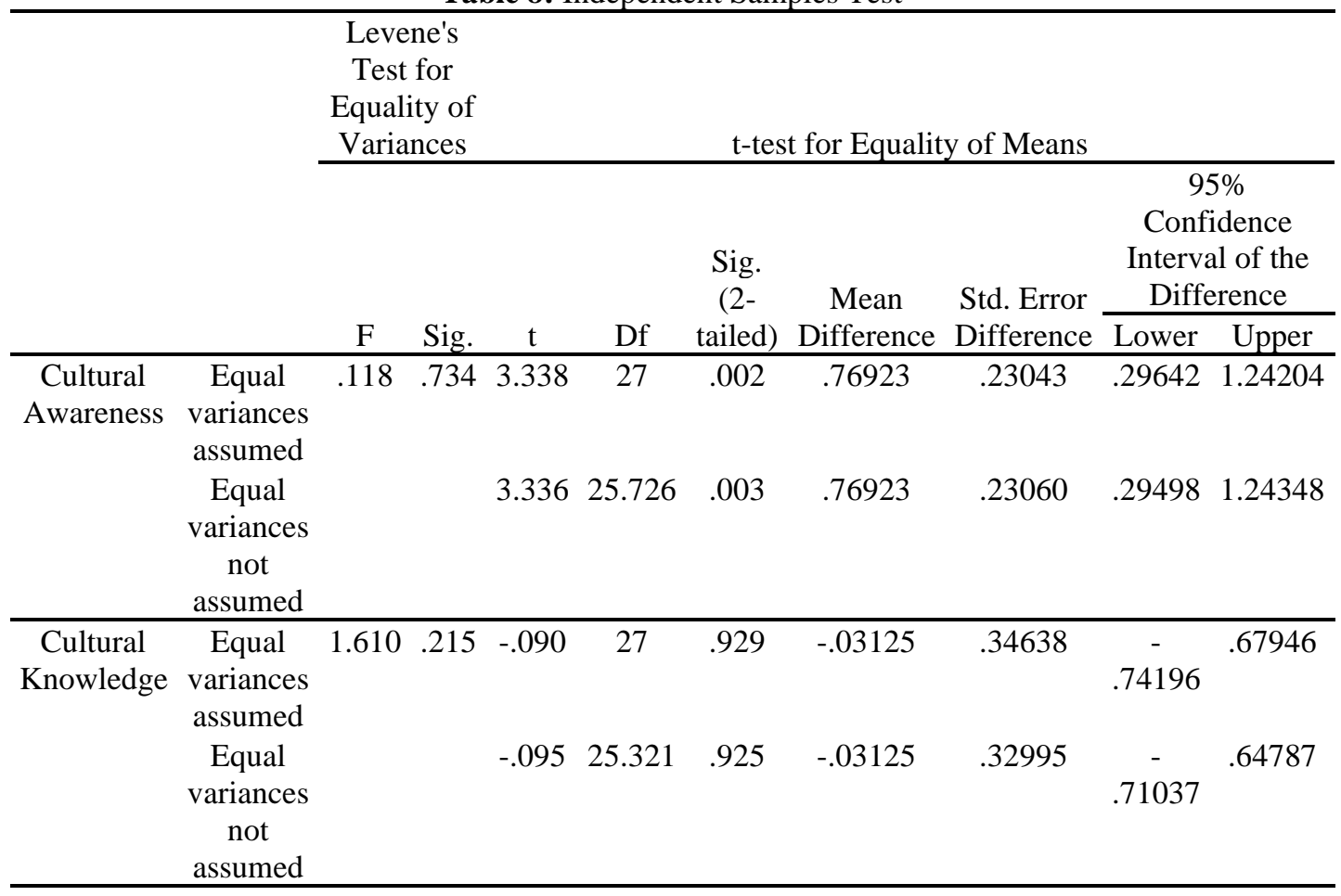

The student scores for each item between Group 1 and Group 2 were also compared. The results are presented in Table 9 and depict the questions for which the differences were significant between Group 1 and Group 2. Table 9 suggests that in Q7, Q8, Q12, and Q13, students who completed the multicultural education course (Group 1) scored significantly higher than the students who did not take the course (Group 2). All these four questions belonged to the cultural attitude awareness subscale. 
Table 9 : Statistics per Item

\begin{tabular}{|c|c|c|c|c|c|c|}
\hline Item & $\begin{array}{c}\text { Mean } \\
\text { (WithTE, } \\
\text { Yes) } \\
\end{array}$ & $\begin{array}{c}\text { Std } \\
\text { (WithTE, } \\
\text { Yes) } \\
\end{array}$ & $\begin{array}{c}\text { Mean } \\
\text { (WithTE, } \\
\text { No) }\end{array}$ & $\begin{array}{c}\text { Std } \\
\text { (WithTE, } \\
\text { No) } \\
\end{array}$ & $\begin{array}{c}\text { Independent } \\
\text { T-test } \\
\text { pvalue }\end{array}$ & Questions \\
\hline Q1 & 4.6875 & 1.5370 & 3.7692 & .8321 & .0516 & \\
\hline $\mathrm{Q} 2$ & 4.5000 & 1.5055 & 4.6154 & .6504 & .7849 & \\
\hline Q6 & 4.8125 & 1.7970 & 3.9231 & 1.0377 & .1082 & \\
\hline Q8 & 5.6875 & .6021 & 4.8462 & 1.3540 & .0090 & $\begin{array}{l}\text { I am sensitive to } \\
\text { situations (on campus, or } \\
\text { in other areas) that are not } \\
\text { welcoming to members of } \\
\text { certain groups } \\
\text { I become more aware of } \\
\text { cultural differences when } \\
\text { I interact with people } \\
\text { from a culture that is } \\
\text { unfamiliar to me }\end{array}$ \\
\hline Q11 & 5.2500 & .5774 & 5.0000 & .4082 & .1844 & \\
\hline Q13 & 5.6250 & 1.0954 & 5.0000 & 1.1929 & .0034 & $\begin{array}{c}\text { I have opportunities to } \\
\text { interact with people from } \\
\text { other cultural and ethnic } \\
\text { groups } \\
\text { I plan to have academic } \\
\text { coursework, fieldwork } \\
\text { experiences, or research } \\
\text { projects related to } \\
\text { culturally diverse groups } \\
\text { in the future }\end{array}$ \\
\hline Q14 & 5.5625 & .7274 & 5.3077 & .4804 & .2687 & \\
\hline Q16 & 2.3125 & 1.4009 & 2.9231 & .8623 & .1622 & \\
\hline Q18 & 3.8125 & 1.8337 & 3.6154 & 1.4456 & .7487 & \\
\hline Q19 & 5.3125 & 1.2500 & 5.0000 & .4082 & .3591 & \\
\hline Q22 & 3.4375 & 1.6721 & 3.4615 & .7763 & 9597 & \\
\hline
\end{tabular}

It is interesting to note that the result of Q7 (I am sensitive to situations on campus, or in other areas that are not welcoming to members of certain groups) points towards diverse campus and community environment where 
students get the opportunity to interact with their culturally diverse peers, classmates, and conduct their research project. This indicates that a students' attitude awareness has become more culturally sensitized, and they could relate better to the challenges faced by the children and their families of different cultures when they explore and identify the strengths and assets of different community agencies that work with them.

The result of Q8 (I become more aware of cultural differences when I interact with people from a culture that is unfamiliar to me) further corroborates how that it is the critical understanding of the diverse communities through the agencies working with them that brings a change in the attitude of students as regarding their cultural awareness. Thus, they were able to recognize the cultural differences much better.

The result of Q13 (I plan to have academic coursework, fieldwork experiences, or research projects related to culturally diverse groups in the future) demonstrate the benefit of the community exploration research project that enhanced the students' attitude awareness, thereby making them excited to engage in such projects in the future that can make them effective culturally competent teachers.

The result of Q12 was different (I have opportunities to interact with people from other cultural and ethnic groups) as the difference in this question is most likely due to the community exploration research project activities provided in the multicultural education course. Therefore, applying classroom knowledge to practice through research in the observational activities of the diverse community agencies seemed to be beneficial for the development of critical consciousness, and perhaps this influenced the students' responses on Qs. 7, 8, and 13.

In contrast, none of the questions in the cultural knowledge subscale had significant differences between Group 1 or Group 2. This is possibly suggesting that the knowledge about cultural diversity imparted to students over the years through the education system and media in the US has been quite effective (Wells et al., 2020). Also, simply imparting the knowledge about cultural diversity, although important, cannot alone make students fully culturally competent. It is through the critical understanding of different cultures, to which an individual can relate on a personal level, that makes the difference and creates effective culturally competent teachers by incorporating cultural attitude awareness. The nature of these experiences with culturally diverse people, whether positive or negative, and how it affects the development of cultural competency is a subject of future studies with a larger student population.

These results indicate that the multicultural course was successful in influencing the attitude of students to make them more culturally aware and, hence, successful in incorporating one of the attributes of cultural competency. 
However, this does not seem to be the case with the attribute of cultural knowledge. It is to be noted here that the sample size was small, and hence to drive generalizable findings, a longitudinal study with a larger sample size would be useful for emphatically deciding the effectiveness of the multicultural education course on the overall cultural competency construct, as well as on its two subscales (i.e., cultural attitude awareness and cultural knowledge).

\section{Moderation of Cultural Attitude Awareness and Cultural Knowledge by GPA and Age}

To understand whether completing a multicultural education course on cultural attitude awareness and cultural knowledge is moderated by Age and GPA, we utilized mixed-design ANOVA, which Hair (2010) recommends as an appropriate choice for comparing two groups, while accounting for additional factors that further divide the two groups. Concerning the cultural attitude awareness and cultural knowledge, the descriptive statistics for Group 1 and Group 2 is further subdivided by Age and GPA. Categories are presented in Error! Reference source not found. and Table 12, respectively.

Table 10 : Descriptive Statistics

Dependent Variable: Cultural Awareness

\begin{tabular}{|c|c|c|c|c|c|}
\hline Age & GPA & WithTE & Mean & Std. Deviation & $\mathrm{N}$ \\
\hline \multirow[t]{9}{*}{$18-20$} & $3.00-3.59$ & No & 3.8889 & .00000 & 6 \\
\hline & & Yes & 4.4815 & .44905 & 3 \\
\hline & & Total & 4.0864 & .37176 & 9 \\
\hline & $3.60-4.00$ & No & 5.1667 & .33333 & 4 \\
\hline & & Yes & 5.4861 & .31949 & 8 \\
\hline & & Total & 5.3796 & .34640 & 12 \\
\hline & Total & No & 4.4000 & .68733 & 10 \\
\hline & & Yes & 5.2121 & .57618 & 11 \\
\hline & & Total & 4.8254 & .74251 & 21 \\
\hline \multirow[t]{9}{*}{$21-24$} & $3.00-3.59$ & $\mathrm{No}$ & 4.7778 & .31427 & 2 \\
\hline & & Yes & 4.0000 & . & 1 \\
\hline & & Total & 4.5185 & .50103 & 3 \\
\hline & $3.60-4.00$ & No & 4.3333 &. & 1 \\
\hline & & Yes & 5.7778 & .00000 & 2 \\
\hline & & Total & 5.2963 & .83395 & 3 \\
\hline & Total & No & 4.6296 & .33945 & 3 \\
\hline & & Yes & 5.1852 & 1.02640 & 3 \\
\hline & & Total & 4.9074 & .74839 & 6 \\
\hline \multirow[t]{4}{*}{31 or older } & $3.60-4.00$ & Yes & 5.3333 & .47140 & 2 \\
\hline & & Total & 5.3333 & .47140 & 2 \\
\hline & Total & Yes & 5.3333 & .47140 & 2 \\
\hline & & Total & 5.3333 & .47140 & 2 \\
\hline Total & $3.00-3.59$ & No & 4.1111 & .42828 & 8 \\
\hline
\end{tabular}




\begin{tabular}{ccccc} 
& Yes & 4.3611 & .43862 & 4 \\
& Total & 4.1944 & .42935 & 12 \\
\hline $3.60-4.00$ & No & 5.0000 & .47140 & 5 \\
& Yes & 5.5093 & .32293 & 12 \\
& Total & 5.3595 & .42949 & 17 \\
\hline Total & No & 4.4530 & .61941 & 13 \\
& Yes & 5.2222 & .61531 & 16 \\
& Total & 4.8774 & .72029 & 29 \\
\hline
\end{tabular}

Table 11 : Tests of Between-Subjects Effects

Dependent Variable: Cultural Awareness

\begin{tabular}{ccccccc}
\hline Source & $\begin{array}{c}\text { Type III Sum } \\
\text { of Squares }\end{array}$ & df & $\begin{array}{c}\text { Mean } \\
\text { Square }\end{array}$ & F & Sig. & $\begin{array}{c}\text { Partial Eta } \\
\text { Squared }\end{array}$ \\
\hline Corrected & $10.902^{\mathrm{a}}$ & 6 & 1.817 & 11.028 & .000 & .750 \\
Model & & & & & & \\
Intercept & 363.526 & 1 & 363.526 & 2206.311 & .000 & .990 \\
WithTE & .262 & 1 & .262 & 1.591 & .220 & .067 \\
Age $*$ & .272 & 3 & .091 & .551 & .653 & .070 \\
WithTE & & & & & & .642 \\
GPA * & 6.507 & 2 & 3.253 & 19.745 & .000 &. \\
WithTE & 3.625 & 22 & .165 & & & \\
Error & 704.407 & 29 & & & & \\
Total & 14.527 & 28 & & & & \\
Corrected & & & & & & \\
Total & & & & & &
\end{tabular}

a. R Squared $=.750$ (Adjusted R Squared $=.682$ )

Table 12 : Descriptive Statistics

Dependent Variable: Cultural Knowledge

\begin{tabular}{|c|c|c|c|c|c|}
\hline Age & GPA & WithTE & Mean & Std. Deviation & $\mathrm{N}$ \\
\hline \multirow[t]{9}{*}{$18-20$} & $3.00-3.59$ & No & 4.2500 & .00000 & 6 \\
\hline & & Yes & 3.9167 & .57735 & 3 \\
\hline & & Total & 4.1389 & .33333 & 9 \\
\hline & $3.60-4.00$ & No & 3.1875 & .71807 & 4 \\
\hline & & Yes & 4.0000 & .76765 & 8 \\
\hline & & Total & 3.7292 & .82199 & 12 \\
\hline & Total & No & 3.8250 & .68769 & 10 \\
\hline & & Yes & 3.9773 & 69331 & 11 \\
\hline & & Total & 3.9048 & .67766 & 21 \\
\hline \multirow[t]{9}{*}{$21-24$} & $3.00-3.59$ & No & 3.7500 & .70711 & 2 \\
\hline & & Yes & 3.0000 & . & 1 \\
\hline & & Total & 3.5000 & .66144 & 3 \\
\hline & $3.60-4.00$ & No & 3.0000 & . & 1 \\
\hline & & Yes & 3.0000 & 2.82843 & 2 \\
\hline & & Total & 3.0000 & 2.00000 & 3 \\
\hline & Total & No & 3.5000 & .66144 & 3 \\
\hline & & Yes & 3.0000 & 2.00000 & 3 \\
\hline & & Total & 3.2500 & 1.36015 & 6 \\
\hline
\end{tabular}




\begin{tabular}{cccccc}
31 or older & $3.60-4.00$ & Yes & 3.3750 & 1.59099 & 2 \\
& & Total & 3.3750 & 1.59099 & 2 \\
\cline { 2 - 6 } & \multirow{2}{*}{ Total } & Yes & 3.3750 & 1.59099 & 2 \\
& & Total & 3.3750 & 1.59099 & 2 \\
\hline \multirow{2}{*}{ Total } & $3.00-3.59$ & No & 4.1250 & .35355 & 8 \\
& & Yes & 3.6875 & .65749 & 4 \\
& & Total & 3.9792 & .49381 & 12 \\
\cline { 2 - 6 } & \multirow{2}{*}{$3.60-4.00$} & No & 3.1500 & .62750 & 5 \\
& & Yes & 3.7292 & 1.22687 & 12 \\
& & Total & 3.5588 & 1.09875 & 17 \\
\cline { 2 - 6 } & & No & 3.7500 & .66927 & 13 \\
& \multirow{2}{*}{ Total } & Yes & 3.7188 & 1.09116 & 16 \\
& & Total & 3.7328 & .91107 & 29 \\
\hline
\end{tabular}

\section{Cultural Attitude Awareness is Moderated by GPA but not Age}

Table 11 depicts the moderation effects of Age and GPA by looking at the product terms (WithTE*Age and WithTE*GPA). Table 11 suggests significant interaction effect for GPA, F $(2,29)=19.745, \mathrm{p}<.001$. The partial eta squared (effect size) of 0.642 indicates a strong moderation effect according to Cohen (1988). In contrast, Age was not a significant moderator $(p>.05)$. Though the results for the 'WithTE' row in Table 11 indicates the effect of completing the course on cultural attitude awareness is not significant. However, as pallant (2020) points out, it is not appropriate to interpret the effects of the 'WithTE' variable alone when interaction effects such as in this case due to GPA are present. Hence, we only refer to independent T-tests performed in the previous section to check if the cultural attitude awareness was significantly different between Group 1 and Group 2.

Furthermore, to analyze how GPA categories differed in terms of cultural awareness, Error! Reference source not found.(a) depicts the estimated marginal means with regards to cultural attitude awareness for Group 1 ('WithTE' = Yes) and Group 2 ('WithTE' = No) for the GPA categories. The figure shows a larger increase in scores for students in the $3.60-4.00$ category as compared to the 3.00-2.59 category among the students who completed the multicultural education course. Those who have higher GPA scores increase their score of cultural awareness from 5.09 to 5.48, while those with lower GPA increase their score from 4.18 to 4.30 . This is perhaps an indicative of higher cultural tolerance and acceptance demonstrated among academically high-achieving students (Verkuyten et al., 2019). Furthermore, a steeper slope for Group 1 indicates that the multicultural education course has been useful in increasing the cultural attitude awareness of the students as compared to the students who did not complete this course. This additionally corroborates the findings in the previous section concerning a significant increase in cultural attitude awareness of the students who took the course. In 
contrast, Error! Reference source not found.(b) suggests a higher cultural attitude awareness scores of the students in Group 1 as compared to Group 2 for 18-20 and 21-24 Age categories. However, the moderation effect of age on the cultural attitude awareness seems to be inconclusive. This may be due to the limited sample size of the study.

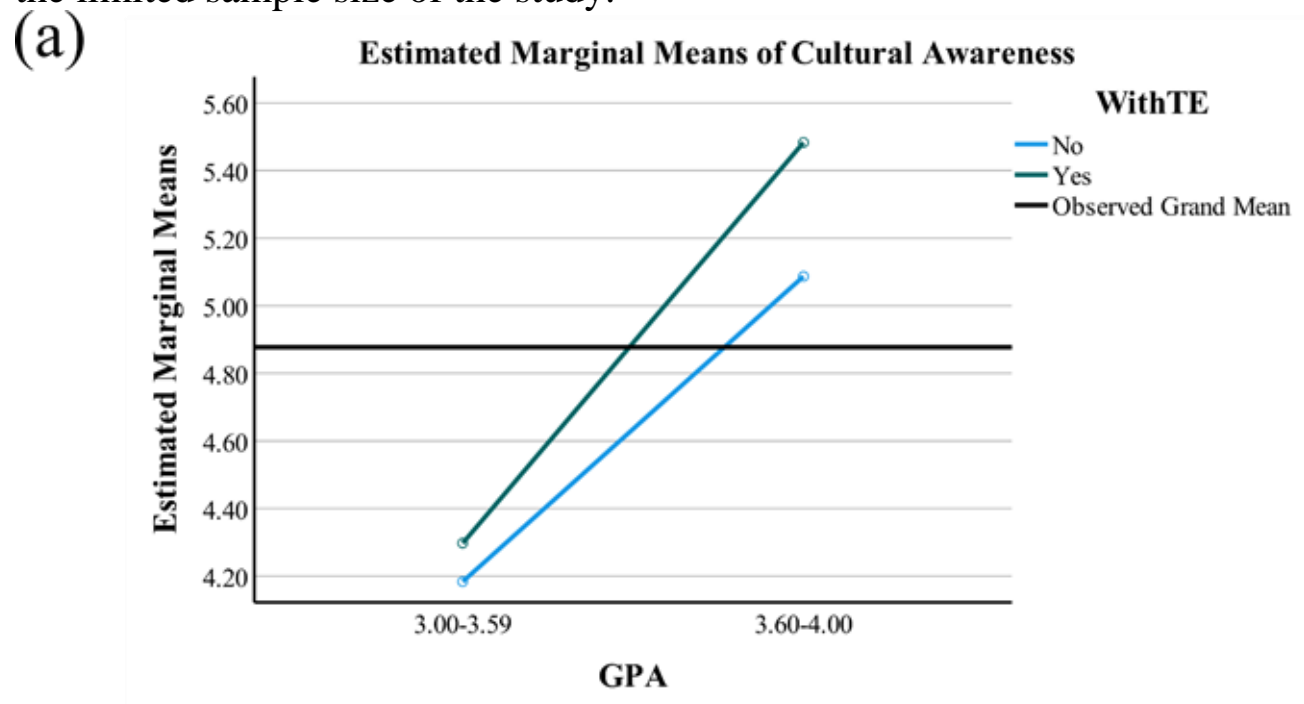

(b)

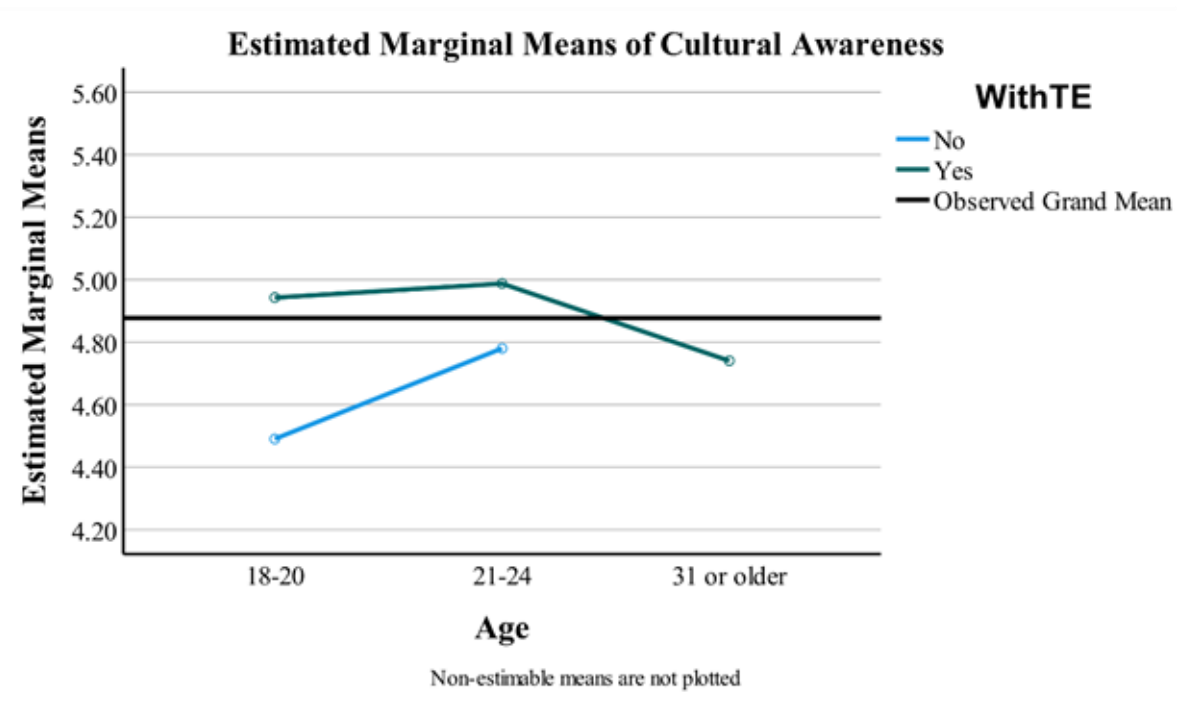

Figure 1: Estimated marginal means with regards to cultural attitude awareness for Group 1 ('WithTE' = Yes) and Group 2 ('WithTE' = No) for the (a) GPA and (b) Age categories. 
(a)

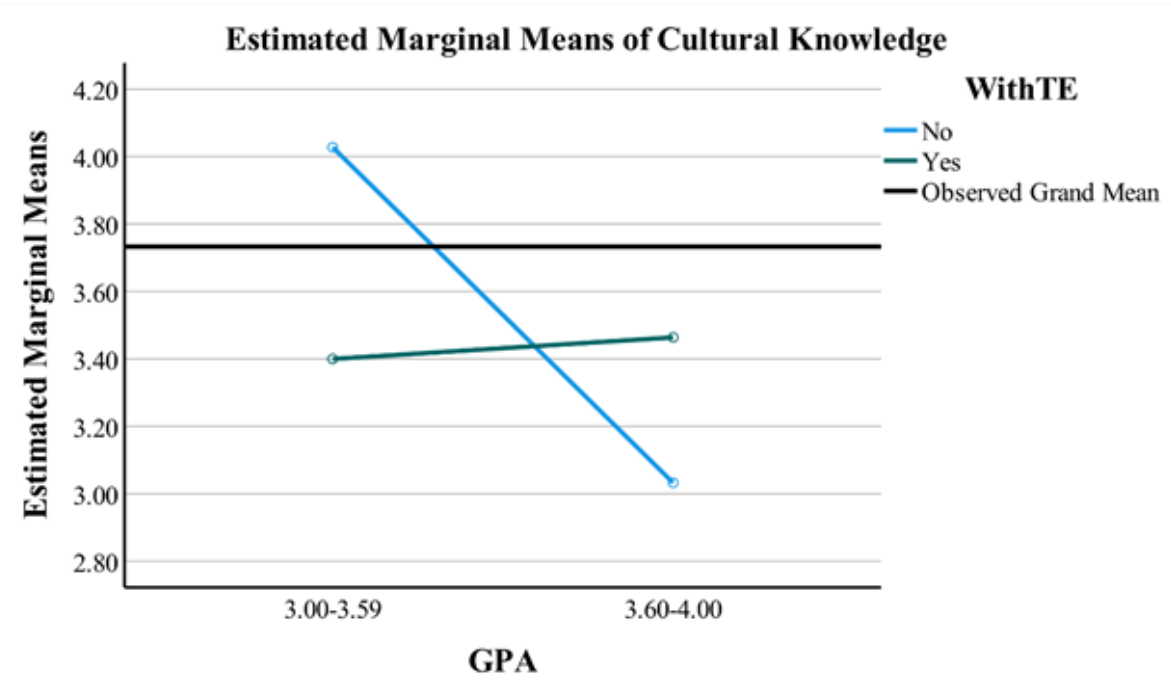

(b)

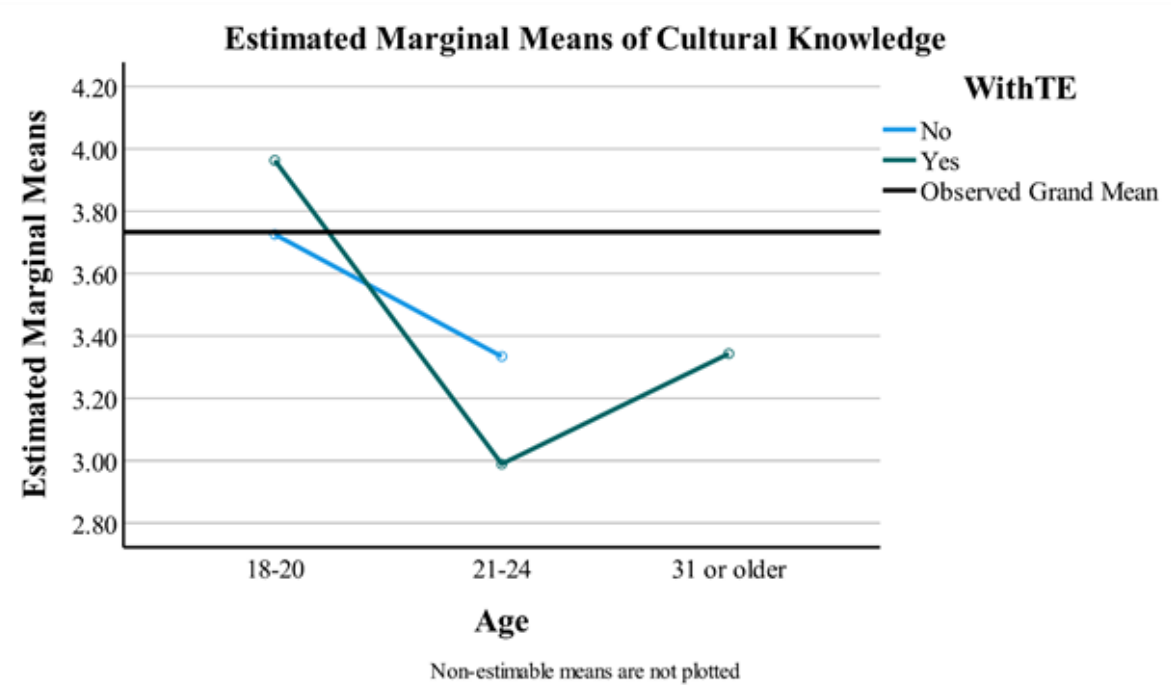

Figure 2: Estimated marginal means with regards to cultural knowledge for Group 1 ('WithTE' = Yes) and Group 2 ('WithTE' = No) for the (a) GPA and (b) Age categories.

\section{Cultural Knowledge is not Moderated by GPA or Age}

Table 13 depicts the moderation effects of Age and GPA on cultural knowledge, which suggest no moderation effect due to either Age or GPA ( $p$ $>$.05). To check how Age and GPA categories differed in terms of cultural knowledge, the estimated marginal means of cultural knowledge for Group 1 and Group 2 was plotted for GPA categories in Error! Reference source not found.(a) and Age categories in Error! Reference source not found.(b). Comparing the GPA category in Error! Reference source not found.(a), the 
opposite effect of taking the multicultural education course is seen on the cultural knowledge scores, and no moderation effect of GPA on cultural knowledge is suggested. Error! Reference source not found.(b) shows similar results as Error! Reference source not found.(a) and depicts the opposite effect of taking the multicultural course on cultural knowledge when comparing age categories, and no moderation effect of age on cultural knowledge is depicted either. It may be so because no significant difference was demonstrated between Group 1 and Group 2 concerning the cultural knowledge, and additionally, due to lack of statistical power because of the limited size of the data.

Table 13 : Tests of Between-Subjects Effects Dependent Variable: Cultural Knowledge

\begin{tabular}{ccccccc}
\hline Source & $\begin{array}{c}\text { Type III Sum } \\
\text { of Squares }\end{array}$ & df & $\begin{array}{c}\text { Mean } \\
\text { Square }\end{array}$ & F & Sig. & $\begin{array}{c}\text { Partial Eta } \\
\text { Squared }\end{array}$ \\
\hline Corrected & $5.817^{\text {a }}$ & 6 & .970 & 1.224 & .332 & .250 \\
Model & & & & & & \\
Intercept & 193.480 & 1 & 193.480 & 244.289 & .000 & .917 \\
WithTE & .039 & 1 & .039 & .049 & .827 & .002 \\
Age ${ }^{*}$ & 2.880 & 3 & .960 & 1.212 & .329 & .142 \\
WithTE & & & & & & .149 \\
GPA ${ }^{*}$ & 3.045 & 2 & 1.523 & 1.922 & .170 & .149 \\
WithTE & & & & & & \\
Error & 17.424 & 22 & .792 & & & \\
Total & 427.313 & 29 & & & & \\
Corrected & 23.241 & 28 & & & & \\
Total & & & & & & \\
\hline
\end{tabular}

a. R Squared $=.250$ (Adjusted R Squared $=.046)$

Overall, the results in this section indicate a significant moderation effect of GPA on the cultural attitude awareness of the students. A stronger moderation effect of GPA was found among the students who completed the multicultural education course as compared to those who did not complete the course. The moderation effect of GPA on cultural knowledge was not significant concerning age, and the moderation effect was also not significant for either cultural attitude awareness or cultural knowledge. However, for more conclusive evidence about the moderation effects of age, GPA, racial and other demographic variables, future investigative studies with more survey participants are recommended.

Before concluding this article, it is appropriate to note some limitations of the study. Due to the small sample size, the findings may not be generalized to a larger population of students of different ethnic backgrounds and genders. Another limitation was that the subjects were undergraduate students, hence the influence of multicultural education courses on students of other grade levels (e.g., high school, graduate school) could not be determined in this 
study. However, as indicated in this article, we expect that the increase in cultural attitude awareness of the students due to the exploratory research aspect of multicultural education courses would perhaps apply to other grade levels too. This is because previous research has shown that real-life experiences play an important role in bringing significant changes in the attitude and mindset of an individual (Services, 2016). Since the home and community environment of the subjects were not controlled and the students were not observed during their community exploration research project activity, which was a limitation to this study. A detailed study, accounting demographic, ethnic, and education variables is recommended to rigorously investigate the effect of the multicultural education course on the attributes of cultural competency and to derive generalizable results.

\section{Conclusion}

In conclusion, the results of the present study have revealed a positive impact of a multicultural education course on the cultural competence of the students. A significant difference in the cultural attitude awareness of the subjects has been noticed which can be attributed to the efficacy of the community exploratory project. This research project involved activities designed for student engagement using experimentation, reflection, and thinking (Kolb, 1984). The findings of this study have brought out the effectiveness of the multicultural education course and the utility of incorporating community exploration research projects to enhance the learning of the students on their cultural attitude awareness. The research emphasizes the importance of a positive and engaging experience between the culturally diverse community in a manner that can enable the students to learn from each other and the other diverse groups (Sandell \& Tupy, 2015). Thus, the community exploration projects as in the present study could enhance the educational benefits of a multicultural course.

Future investigation can shed light on how the students in a culturally diverse classroom can come together across racial/ethnic lines and participate in their intergroup assignments to respond to the activities through their critical reflections and how the educators/teachers could create conditions that would foster better intercultural understanding.

The components of culturally relevant pedagogy, student learning, cultural competence in teaching and critical consciousness, are often discussed as separate entities. While the focus of this paper is on cultural competence in teaching, it is important to note that to truly practice culturally relevant pedagogy, the three components i.e., student learning, cultural competence, and critical consciousness must be addressed (Ladson Billings \& King, 2020). Though we realize that other attributes contribute to the cultural competency of a teacher. However, evaluation with regards to the influence of a 
multicultural education course on the integration of all the cultural competency attributes would require studies on a much larger scale with more participant data. The results have been presented in this study to document the efforts so as to provide opportunities for exploratory community activities, and research projects to preservice teachers to enact the aspects of culturally relevant pedagogy. Thus, this paper inspires future studies to drive home the importance of cultural competency to the budding generation of K-12 teachers.

\section{References:}

1. Bennett, C. (2019). Comprehensive Multicultural Education: Theory and Practice. Pearson Education, Inc.

2. Chiang, L. (2013). An Assessment of Diversity Competence among College Seniors: An Exploratory Study.

https://scholarworks.uno.edu/cgi/viewcontent.cgi?article=2770\&cont ext=td

3. Chiu, C. Y., Lonner,W., Matsumoto, D. \& Ward, C. (2013). CrossCultural Competence: Theory, Research, and Application. Journal of Cross-Cultural Psychology, 44, 843-848. https://doi.org/10.1177/0022022113493716

4. Civitillo, S., Juang, L. P. \& Schachner, M. K. (2018). Challenging Beliefs about Cultural Diversity in Education: A synthesis and critical review of trainings with pre-service teachers. Educational Research Review, 24, 67-83.

https://doi.org/https://doi.org/10.1016/j.edurev.2018.01.003

5. Cohen, J. (1988). Statistical power analysis for the behavioral sciences. L. Erlbaum Associates.

6. Drame, I., Wingate, L., Unonu, J., Turner, M., Taylor, M. D., Bush, A., Jarvis, M., \& Cawthorne, T. A. (2021). The association between students' emotional intelligence, cultural competency, and cultural awareness. Currents in Pharmacy Teaching and Learning. https://doi.org/https://doi.org/10.1016/j.cptl.2021.06.030

7. Ewing, D. L., Monsen, J. J. \& Kielblock, S. (2018). Teachers' attitudes towards inclusive education: a critical review of published questionnaires. Educational Psychology in Practice, 34(2), 150-165. https://doi.org/10.1080/02667363.2017.1417822

8. Fasching Varner, K. J., Denny, R. K., Stone, M. P., Stewart, L. M., Albornoz, C. F., Mora, R., Olave, F., Yacoman, M., Yang, A. \& Denny, M. A. (2018). Love in a "Glocal" World: Living and Learning to Teach Through Study Abroad. Multicultural Perspectives, 20(3), 135-147. https://doi.org/10.1080/15210960.2018.1480955 
9. Goodman, D. (2020). Cultural Competence for Equity and Inclusion: A Framework for Individual and Organizational Change. 10, 5-24.

10. Hair, J. (2010). Multivariate data analysis. Prentice Hall.

11. Hodge, S. R. \& Collins, F. G. (2019). Physical Education Teachers' Understandings of Culturally Relevant Pedagogy in Teaching Black Male Students. Multicultural Learning and Teaching, 14(1), 20150016. https://doi.org/doi:10.1515/mlt-2015-0016

12. Howard, T. (2003). Culturally Relevant Pedagogy: Ingredients for Critical Teacher Reflection. Theory Into Practice - THEORY PRACT, 42, 195-202. https://doi.org/10.1207/s15430421tip4203_5

13. Hultsjö, S., Bachrach-Lindström, M., Safipour, J. \& Hadziabdic, E. (2019). "Cultural awareness requires more than theoretical education" - Nursing students' experiences. Nurse Education in Practice, 39, 7379. https://doi.org/https://doi.org/10.1016/j.nepr.2019.07.009

14. IBM Corp. (n.d.). IBM SPSS Statistics for Windows [Computer software]. https://www.ibm.com/analytics/spss-st...

15. Kahu, E. R. \& Nelson, K. (2018). Student engagement in the educational interface: understanding the mechanisms of student success. Higher Education Research \& Development, 37(1), 58-71. https://doi.org/10.1080/07294360.2017.1344197

16. Kolb, D. (1984). Experiential learning : experience as the source of learning and development. Prentice-Hall.

17. Krzych, S. (2021). Beyond bias : conservative media, documentary form, and the politics of hysteria. Oxford University Press.

18. Ladson Billings, G. (2000). Culturally relevant pedagogy in Africancentered schools: Possibilities for progressive educational reform. African-Centered Schooling in Theory and Practice, 187-198.

19. Ladson Billings, G. (2021). I'm Here for the Hard Re-Set: Post Pandemic Pedagogy to Preserve Our Culture. Equity \& Excellence in Education, 54(1), 68-78.

https://doi.org/10.1080/10665684.2020.1863883

20. Ladson Billings, G. \& King, J. E. (2020). African-Centered Education: Theory and Practice. Stylus Publishing, LLC.

21. Mayfield, V. (2020). Cultural competence now : 56 exercises to help educators understand and challenge bias, racism, and privilege. ASCD.

22. Min, M., Lee, H., Hodge, C. \& Croxton, N. (n.d.). What Empowers Teachers to Become Social Justice-Oriented Change Agents? Influential Factors on Teacher Agency toward Culturally Responsive Teaching. Education and Urban Society, O(0), 00131245211027511. https://doi.org/10.1177/00131245211027511 
23. Nuri Robins, K., Lindsey, D., Terrell, R. \& Lindsey, R. (2007). Cultural Proficiency: Tools for Secondary School Administrators and Principal Leadership.

24. Pallant (2020). SPSS SURVIVAL MANUAL. OPEN UNIV Press.

25. Sandell, E. J. \& Tupy, S. J. (2015). Where cultural competency begins: Changes in undergraduate students' intercultural competency. International Journal of Teaching and Learning in Higher Education, 27(3), 364-381.

26. Services, U. S. (2016). Treatment improvement protocol - improving cultural competence - tip 59. LULU COM.

27. Shallcross, L., Whyte, A. K., Aubrecht, A. L., McCullough, C. A., Lewis, J. W., Thompson Ochoa, D., Tovar, L. Z., Conley, A. H., Nassar McMillan, S., Willow, R. A. \& others. (2013). Counseling Today.

28. Tehee Melissa, Isaacs, D. \& D. R. M. M. (2020). The Elusive Construct of Cultural Competence. In F. R. and S. J. Benuto Lorraine T. and Gonzalez (Ed.), Handbook of Cultural Factors in Behavioral Health: A Guide for the Helping Professional (pp. 11-24). Springer International Publishing. https://doi.org/10.1007/978-3-030-322298_2

29. Tervalon, M. \& Murray Garcia, J. (1998). Cultural Humility versus Cultural Competence: A critical distinction in defining physician training outcomes in multicultural education. Journal of Health Care for the Poor and Underserved, 9(2), 117-125.

30. Thakur, N., Lovinsky Desir, S., Bime, C., Wisnivesky, J. P. \& Celedón, J. C. (2020). The Structural and Social Determinants of the Racial/Ethnic Disparities in the U.S. COVID-19 Pandemic. What's Our Role? American Journal of Respiratory and Critical Care Medicine, 202(7), 943-949. https://doi.org/10.1164/rccm.202005$1523 \mathrm{PP}$

31. Verkuyten, M., Yogeeswaran, K. \& Adelman, L. (2019). Intergroup Toleration and Its Implications for Culturally Diverse Societies. Social Issues and Policy Review, 13(1), 5-35. https://doi.org/10.1111/sipr.12051

32. Vilagut, G. (2014). Test-Retest Reliability. In A. C. Michalos (Ed.), Encyclopedia of Quality of Life and Well-Being Research (pp. 66226625). Springer Netherlands. https://doi.org/10.1007/978-94-0070753-5_3001

33. Wells, - Amy Stuart, Wells, A. S., Foundation, - By The Century, Kashen, - By Julie Potter, - By Halley Osborn, - By Caroline \& Shireman, - By Robert. (2020). How Racially Diverse Schools and Classrooms Can Benefit All Students. In The Century Foundation. 
https://tcf.org/content/report/how-racially-diverse-schools-andclassrooms-can-benefit-all-students/?agreed $=1$

34. Yamada, M. (2010). Building Racial and Cultural Competence in the Classroom: Strategies From Urban Educators by Karen Monheim Teel and Jennifer E. Obidah (Eds.). Diaspora, Indigenous, and Minority Education, 4(3), 208-210.

https://doi.org/10.1080/15595690903227780 